\title{
Optimalisasi Digital Marketing melalui Facebook Ads di Kelurahan Purwanegara
}

\author{
Siti Barokah1, Oryz Agnu Dian Wulandari'2, Mulat Triwinoto Sari ${ }^{3}$, Ivan Fadhil Yuditama ${ }^{4}$ \\ 1,2,3,4Universitas Amikom Purwokerto \\ email: 1siti.barokah@amikompurwokerto.ac.id, 2oryzdian@amikompurwokerto.ac.id, \\ ${ }^{3}$ mulattriws123@gmail.com, 4ivanfadhil7@gmail.com
}

\begin{abstract}
Abstrak
Saat ini dunia periklanan menggunakan media sosial menjadi salah satu strategi yang dianggap efektif dan efisien untuk melakukan pemasaran secara digital karena dirasa dapat mengurangi anggaran dalam mempublikasikan produk atau jasa. Selain itu, media sosial juga terbukti menjadi media promosi yang ampuh karena interaktif, fleksibel, dan menyajikan fitur-fitur mendukung promosi produk maupun jasa itu sendiri. Salah satu fitur yang ditawarkan oleh Facebook adalah Facebook Ads, yaitu fitur yang ditawarkan oleh Facebook untuk mengiklankan halaman Facebook dengan jangkauan yang dapat ditentukan dan dapat diatur oleh pemasang iklan tersebut. Kegiatan pengabdian kepada masyarakat ini bertujuan untuk memperkenalkan dan memotivasi para pegiat bisnis online di Kelurahan Purwanegara dalam memanfaatkan dan mengoptimalkan pemasaran secara digital melalui Facebook Ads. Metode yang digunakan dalam kegiatan ini adalah ceramah dan diskusi menggunakan power point dengan alat bantu LCD proyektor. Luaran yang diharapkan dengan adanya kegiatan pengabdian ini adalah para pegiat bisnis online dapat lebih mengenal dan mengoptimalkan fungsi fitur-fitur yang telah disediakan oleh media sosial Facebook untuk kegiatan promosi bisnis yang sedang digeluti.
\end{abstract}

Kata Kunci: Digital Marketing, Media Sosial, Facebook Ads.

\section{Abstract}

Currently the world of advertising using social media is one strategy that is considered effective and efficient for digital marketing because it is felt that it can reduce the budget in publishing products or services. In addition, social media has also proven to be a powerful promotional media because it is interactive, flexible, and presents features supporting the promotion of products and services themselves. One of the features offered by Facebook is Facebook Ads, which is a feature offered by Facebook to advertise Facebook pages with a range that can be determined and can be set by the advertiser. This community service activity aims to introduce and motivate online business activists in Purwanegara Urban Village to utilize and optimize digital marketing through Facebook Ads. The method used in this activity is lectures and discussions using power points with LCD projector aids. The expected outcome with this community service activity is that online business activists can get to know and optimize the functions of the features provided by Facebook's social media for business promotion activities that are being worked on.

Keywords: Digital Marketing, Social Media, Facebook Ads. 


\section{Pendahuluan}

Saat ini banyak masyarakat yang mulai meninggalkan pemasaran secara konvensional dan beralih kepada pemasaran secara digital atau yang biasa disebut dengan pemasaran digital. Pemasaran secara digital merupakan salah satu media pemasaran yang sedang diminati oleh masyarakat saat ini. Karena, dengan memanfaatkan alat atau media digital dapat menjangkau target konsumen yang lebih luas secara cepat dan tepat. Selain itu, untuk kepentingan usaha dan bisnis pemasaran melalui media digital juga lebih efektif dan efisien dalam penggunaan dana iklan. Salah satu media pemasaran yang banyak disukai daripada media nonvirtual adalah Facebook (Waters et al., 2011). Pengguna media sosial khususnya Facebook saat ini terus meningkat untuk berbagai keperluan seperti sarana mencari teman, sarana komunikasi, sarana mencari maupun berbagi informasi, dan sebagai sarana promosi untuk keperluan bisnis. Kegiatan promosi dibentuk untuk menstimulasi terjadinya kesadaran, ketertarikan, dan akan berakhir dengan pembelian suatu produk (Afifah et al., 2019)

Media sosial Facebook lebih banyak penggunanya diantara media sosial lainnya karena Facebook merupakan salah satu media sosial yang sangat mudah penggunaannya. Sehingga, Facebook bisa digunakan oleh semua kalangan bahkan bagi orang-orang yang baru mengenal jejaring sosial sekalipun. Pernyataan ini juga di dukung dengan pernyataan (Taylor et al., 2011) bahwa Facebook telah berkembang menjadi media sosial yang paling popular dan personalisasinya semakin digunakan sebagai strategi periklanan yang membuat iklan lebih relevan bagi penggunanya. Facebook merupakan situs jejaring sosial yang memiliki layanan bagi penggunanya untuk memposting foto, memposting informasi, memposting komentar dan membagikan konten menarik lainnya di web Facebook. Facebook memiliki beberapa fitur yang dapat dimanfaatkan untuk mengoptimalkan pemasaran secara digital salah satunya yaitu iklan Facebook. Iklan Facebook merupakan fitur yang ditawarkan oleh Facebook sebagai media untuk mempromosikan halaman Facebook yang sebelumnya telah dibuat oleh penggunanya. Sehingga, iklan Facebook atau yang biasa disebut dengan Facebook Ads sangat cocok diterapkan kepada para pegiat usaha online khususnya ibu-ibu yang tergabung dalam PKK kelurahan Purwanegara. Karena, ibu-ibu PKK di kelurahan Purwanegara banyak yang telah menjalankan bisnis secara online melalui media sosial yaitu Facebook. Tetapi, masih banyak yang belum mengerti penggunaan Facebook Ads untuk menjalankan usaha online yang dimiliki. Selama ini, peserta masih menjalankan promosi secara manual yaitu melalui postingan di beranda Facebook pribadi tanpa memanfaatkan fitur promosi iklan Facebook.

Berdasarkan latarbelakang tersebut, maka diadakan pengabdian tentang optimalisasi pemasaran digital melalui Facebook Ads dengan tujuan untuk memperkenalkan sekaligus mengajak para pegiat usaha online mengoptimalkan pemasaran secara digital agar lebih efektif dan efisien. Karena, beriklan di Facebook Ads akan lebih meningkatkan kemampuan konsumen dalam mengenali atau mengingat sebuah merek yang dipromosikan seperti mengenali atau mengingat nama, gambar, logo 
maupun slogan-slogan yang pernah digunakan dalam mempromosikan merek. Setelah mendapatkan nama, para pegiat usaha online tentu akan lebih mudah untuk mencapai tujuan-tujuan bisnis lainnya. Beriklan di Facebook Ads juga dapat disesuaikan dengan target yang diharapkan atau sesuai dengan kriteria bisnis yang dimiliki. Sehingga, target pasar lebih jelas dan tentunya hal ini akan lebih berpotensi untuk mendapatkan konsumen yang tepat sesuai target.

Pemasaran merupakan suatu proses sosial yang didalamnya individu dan kelompok mendapatkan apa yang dibutuhkan dan inginkan dengan menciptakan, menawarkan, dan secara bebas mempertukarkan produk yang bernilai dengan pihak lain (Kotler, 2005). Selain itu, pemasaran juga merupakan suatu sistem keseluruhan dari kegiatan-kegiatan bisnis yang ditunjukkan untuk merencanakan, menentukan harga, mempromosikan dan mendistribusikan barang atau jasa yang memuaskan kebutuhan baik kepada pembeli yang ada maupun pembeli potensial (Stanton, 2001). Pemasaran dapat dilakukan melalui iklan karena pemasaran melalui iklan dapat membangun kesadaran, dapat mengubah perilaku konsumen, dapat membangun loyalitas konsumen, dan dapat membangun nilai tambah sebuah merek (Yunus, Ulani, 2017). Layanan iklan yang terdapat pada Facebook dapat menjadi jembatan bagi pelaku usaha atau pegiat bisnis online untuk dapat memasarkan produk bisnis yang sedang digeluti. Banyaknya pengguna Facebook dari berbagai kalangan ini diharapkan mampu meningkatkan omset penjualan (Asnawi et al., 2017).

\section{Metode}

Kegiatan pengabdian kepada masyarakat di Kelurahan Purwanegara ini menggunakan pendekatan persuasif edukatif dengan metode ceramah dan diskusi (Rahmawati, 2017)melalui tahapan sebagai berikut:

a. Tim pengabdian melakukan survei lokasi pada bulan Oktober 2019.

b. Persiapan kegiatan pengabdian oleh tim untuk merencanakan kegiatan mencakup waktu, materi, dan teknis pelaksanaan kegiatan pengabdian.

c. Konfirmasi dengan ketua PKK Kelurahan Purwanegara sebagai tempat pelaksanaan pengabdian mengenai tempat, sarana prasarana, peserta, dan teknis pelaksanaan kegiatan pengabdian.

d. Pelaksanaan kegiatan pengabdian dibuka oleh Ketua beserta Kader-kader PKK Kelurahan Purwanegara.

e. Penyampaian materi dengan metode ceramah yang digunakan untuk memperkenalkan sekaligus mengajak para peserta dengan menumbuhkan motivasi peserta mengenai pentingnya pemanfaatan media sosial dalam mempromosikan usaha online.

f. Metode ceramah digunakan untuk memberikan pengetahuan dan pemahaman tentang optimalisasi pemasaran secara digital melalui Facebook Ads. Selain itu, metode ini juga digunakan untuk mengenalkan manfaat dan penggunaan beriklan menggunakan fitur Facebook Ads dalam mempromosikan bisnis online yang digeluti.

g. Selanjutnya, dalam kegiatan pengabdian ini peserta diajak berdiskusi untuk mampu mengenal dan termotivasi untuk memanfaatkan dan menggunakan 
Facebook Ads untuk mengoptimalkan pemasaran secara digital melalui media sosial.

Penentuan materi berdasarkan masukan yang didapat dari hasil survei pada bulan Oktober (2019) di Kelurahan Purwanegara menggunakan metode wawancara dengan Ketua PKK Kelurahan Purwanegara. Berdasarkan masukan tersebut, maka tim menentukan tema pengabdian kepada masyarakat yaitu "Optimalisasi digital marketing melalui Facebook Ads di Keluarah Purwanegara".

\section{Hasil dan Pembahasan}

Pada tahap awal kegiatan pengabdian dilaksanakan dengan menemui langsung anggota PKK kelurahan Purwanegara. Dalam pertemuan ini dihasilkan beberapa hal yaitu diantaranya bersepakat untuk mengadakan sosialisasi mengenai optimalisasi digital marketing melalui Facebook Ads untuk menumbuhkan kesadaran masyarakat dalam memanfaatkan dan mengoptimalkan penggunaan media sosial sebagai media promosi dalam bisnis yang dimiliki. Karena, media sosial merupakan sarana komunikasi untuk dapat berinteraksi, berbagi wawasan antar pengguna dalam skala yang luas (Purwanti, 2010). Selain itu, melalui kampanye iklan berbayar pada facebook, sebuah merek dapat menentukan target khalayak dan optimalisasi fitur untuk dapat meningkatkan kesadaran merek terhadap calon konsumen (Aprinta, 2016). Kegiatan dilaksanakan pada hari Sabtu, 25 November 2019 bertempat di Aula Kelurahan Purwanegara, lokasi ini dipilih karena kegiatan Rakor PKK sudah biasa dilaksanakan di Aula Kelurahan Purwanegara. Materi disampaikan dalam bentuk ceramah dengan menggunakan alat bantu Power Point yang disajikan melalui LCD Proyektor. Pada saat pemaparan materi, peserta diarahkan pada pengenalan dan pemahaman mengenai media sosial serta pemanfaatan fitur Facebook Ads yang terdapat di Facebook untuk kegiatan promosi dengan menekankan potensi promosi menggunakan Facebook Ads. Setelah pemaparan materi, kemudian dilanjutkan dengan diskusi.

Peserta kegiatan pengabdian berjumlah 62 orang lebih dari jumlah yang ditargetkan, peserta terdiri dari pegiat usaha online jenis makanan, pakaian, sepatu, skincare dan kosmetik, properti serta percetakan. Pada sesi diskusi antusiasme peserta mulai terlihat, peserta merespon secara positif dengan melontarkan berbagai petanyaan. Banyak hal menarik yang sebelumnya belum diketahui atau sudah diketahui namun belum dioptimalkan dalam penggunaan fitur-fitur yang telah disediakan oleh Facebook sebagai media promosi. Kegiatan pengabdian ini merupakan kegiatan untuk mengenalkan dan memotivasi peserta untuk memanfaatkan dan menggunakan Facebook Ads untuk mengoptimalkan pemasaran secara digital di media sosial karena salah satu strategi komunikasi pemasaran yaitu dengan memanfaatkan semua divisi pemasaran secara optimal, yang nantinya menjadi satu kekuatan kerja yang saling berhubungan dan bersinergi dalam meningkatkan penjualan produk bagi masyarakat di kelurahan Purwanegara (Asse et al., 2018). 


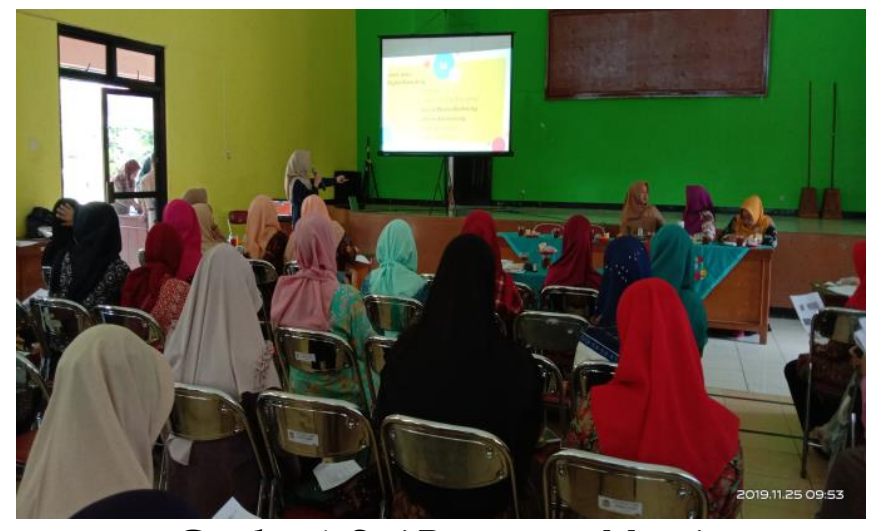

Gambar 1. Sesi Pemaparan Materi

Sumber: Dokumen Pengabdian Kepada Masyarakat 2019

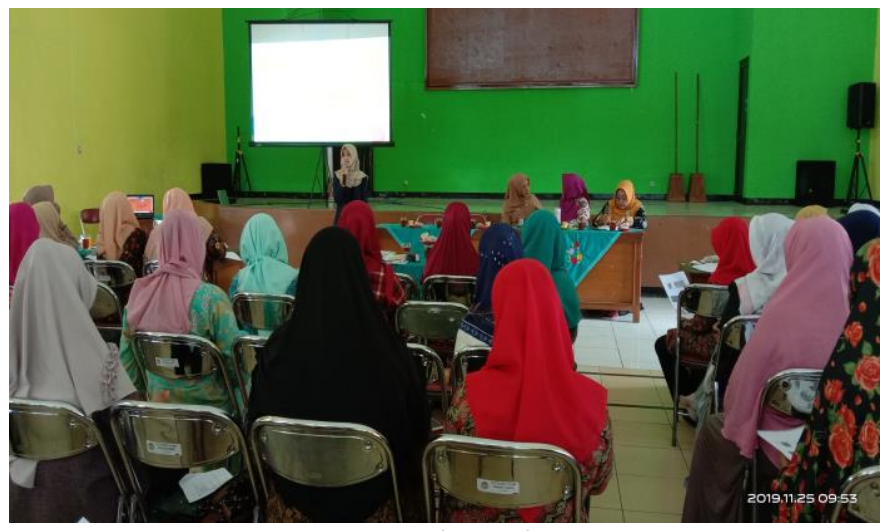

Gambar 1. Sesi Diskusi dengan peserta

Sumber: Dokumen PKM 2019

Kegiatan dilanjutkan dengan pemaparan mengenai tips promosi melalui Facebook Ads, bagaimana menentukan target yang lebih spesifik dan menentukan berbagai tujuan pemasaran yang lebih efektif. Pada sesi ini ditekankan pentingnya menentukan target audience agar iklan dapat menjaring audience sesuai dengan kriteria yang telah ditentukan oleh pegiat bisnis online. Sesi terakhir merupakan penekanan pada kemampuan peserta dalam menuliskan judul, deskripsi, serta foto maupun video yang akan ditampilkan dalam iklan.

Secara umum peserta mengikuti kegiatan pengabdian dengan antusias, hal ini tidak terlepas dari ketertarikan peserta setelah diberi pengetahuan dan pemahaman mengenai promosi menggunakan media sosial dengan mengoptimalkan fitur yang terdapat pada Facebook yaitu Facebook Ads. Setelah kegiatan pengabdian berakhir peserta juga masih terus melontarkan pertanyaan dan meminta personal kontak untuk melakukan diskusi lebih detil lagi.

\section{Simpulan dan Rekomendasi}

Melalui kegiatan pengabdian kepada masyarakat dengan judul "Optimalisasi Pemasaran Digital melalui Facebook Ads di Kelurahan Purwanegara" dapat disimpulkan bahwa secara keseluruhan kegiatan pengabdian berjalan dengan baik. 
Aplikasi facebook dapat di optimalkan penggunaannya sebagai media pemasaran secara digital dengan fitur tambahan facebook ads. Kegiatan pengabdian yang telah dilaksanakan diharapkan dapat memberikan pengetahuan dan informasi mengenai pemasaran produk melalui facebook ads serta memotivasi para peserta untuk mengoptimalkan penggunaan media sosial sebagai media promosi melalui facebook ads. Selain itu, kegiatan pengabdian diharapkan mampu meningkatkan keterampilan peserta dalam menuangkan gagasan dalam bentuk tulisan yang dikombinasikan dengan foto maupun video dalam promosi di media sosial facebook.

Dari kegiatan pengabdian yang telah dilaksanakan, peserta berharap agar kegiatan yang sejenis dapat dilakukan secara bekelanjutan seperti misalnya sosialisasi tentang foto produk, desain kemasan produk, dan pelatihan kewirausahaan.

\section{Daftar Pustaka}

Afifah, L., Najamuddin, M., \& Humaeira, B. (2019). Efektivitas Media Promosi Pada Produk Sandwich Goreng Merek Royal Sandwich. Agribusiness Journal, 13(1), 117. https://doi.org/10.15408/aj.v13i1.11868

Aprinta, G. (2016). Pemanfaatan Facebook Ads Untuk meningkatkan Brand Awareness pada Produk Lokal. Jurnal The Messenger, 8(1), 68. https:// doi.org/10.26623/themessenger.v8i1.310

Asnawi, M., Widiarsih, D., Murialti, N., Darwin, R., Hidayat, M., \& Hadi, M. F. (2017). Tingkatkan Omset Dengan Facebook Ads. Jurnal Pengabdian UntukMu NegeRI, 1(1), 67-71. https:/ / doi.org/10.37859/jpumri.v1i1.38

Asse, Azlam, R., \& Ambo. (2018). Strategi Pemasaran Online (Studi Kasus Facebook Marketing Warunk Bakso Mas Cingkrank di Makassar). Jurnal Komunikasi, 7(2), 219-231.

Kotler, P. (2005). Manajemen Pemasaran (I dan II). PT. Indeks.

Purwanti, A. E. (2010). Pemanfaatan Facebook Sebagai Sarana Promosi Perpustakaan: Studi Kasus Perpustakaan Forum Indonesia Membaca.

Rahmawati, A. (2017). Education Method of Lectures and Discussionstoward Health Cadre Ability in Early. Jurnal Ilmiah Pemenang, 51-56.

Stanton, W. (2001). Prinsip-prinsip Pemasaran (3rd ed.). Erlangga.

Taylor, D. G., Lewin, J. E., \& Strutton, D. (2011). Friends, fans, and followers: Do ads work on social networks? How gender and age shape receptivity. Journal of Advertising Research, 51(1), 258-275. https://doi.org/10.2501/JAR-51-1-258-275

Waters, R. D., Canfield, R. R., Foster, J. M., \& Hardy, E. E. (2011). Applying the dialogic theory to social networking sites: Examining how university health centers convey health messages on Facebook. Journal of Social Marketing, 1(3), 211-227. https://doi.org/10.1108/20426761111170713

Yunus, Ulani, \& R. (2017). Advertising \& Branding (1st ed.). Edu Pustaka. 